Pesq. Vet. Bras. 30(9):754-762, setembro 2010

Tópico de Interesse Geral

\title{
Mastite em pequenos ruminantes no Brasil ${ }^{1}$
}

\author{
Rodolfo de M. Peixoto², Rinaldo Aparecido Mota ${ }^{3}$ e Mateus M. da Costa ${ }^{4 *}$
}

\begin{abstract}
Peixoto R.M., Mota R.A. \& Costa M.M. 2010. [Small ruminant mastitis in Brazil.] Mastite em pequenos ruminantes no Brasil. Pesquisa Veterinária Brasileira 30(9):754-762. Campus Ciências Agrárias, Universidade Federal do Vale do São Francisco, Rodov. BR 407 Km 12, Lote 543, Projeto de Irrigação Senador Nilo Coelho s/n, Petrolina, PE 56300-990, Brazil. E-mail: mateus.costa@univasf.edu.br

The present reviews mastitis in small ruminants, focusing important aspects of etiology, epidemiology, diagnose, control, and prophylaxis. There was a special concern in review studies developed in Brazil, since mastitis results from a combination of many factors such as environmental and management conditions that concur for the action of etiological agents and for the epidemiology of this relevant disease. The prevalence mastitis in goats varies from 22 to $75 \%$, with higher frequency of subclinical cases. In Brazil there are few studies about epidemiologic aspects of mastitis in small ruminants. In the other hand, the disease has growing in importance in meat producing small ruminants, mainly sheep. The mastitis caused by staphylococci is the most prevalent in small ruminants. The zoonotic importance of some milk pathogens such as Staphylococcus aureus emphasizes the importance of the elimination this bacteria by carriers between goat and sheep milk farms. Some diagnostic techniques need more standardization, especially those used in goats that demonstrated some peculiarities. Mastitis control strategies will be discussed include the management of the females and their offspring, milking procedures and vaccination protocols.
\end{abstract}

INDEX TERMS: Mastitis, goats, sheep, etiology, epidemiology, diagnosis, control.

RESUMO.- Este artigo objetivou revisar as informações recentes sobre mastite em pequenos ruminantes, abrangendo etiologia, epidemiologia, aspectos de controle e profilaxia. Houve a preocupação em reunir resultados de estudos desenvolvidos no Brasil, uma vez que a mastite tem a interferência de uma série de fatores, como fatores ambientais e outros decorrentes dos sistemas de manejo empregados, condições essas determinantes para etiologia e epidemiologia da enfermidade. A prevalência da mastite em caprinos varia entre 22 e $75 \%$, sendo que os casos de mastite subclínica são os mais frequentes. Existe uma carência de trabalhos voltados para os aspectos epidemiológicos da enfermidade no nosso país. Contudo, obser-

\footnotetext{
${ }^{1}$ Recebido em 1 de março de 2010.

Aceito para publicação em 12 de abril de 2010

2 Mestrando em Ciência Animal, Universidade Federal do Vale do São Francisco (Univasf), Campus Ciências Agrárias, Rodov. BR 407 Km 12, Lote 543, Projeto de Irrigação Senador Nilo Coelho s/n, Petrolina, PE 56300-990, Brasil.

${ }^{3}$ Departamento de Medicina Veterinária, Universidade Federal Rural de Pernambuco, Rua Dom Manoel de Medeiros s/n, Dois Irmãos, Recife, PE 51171-900, Brasil.

${ }^{4}$ Campus Ciências Agrárias, Univasf, Petrolina, PE. *Autor para correspondência: mateus.costa@univasf.edu.br
}

va-se que a mastite vem assumindo importância cada vez maior nos rebanhos voltados para produção de carne, sendo encontrados resultados de pesquisa, principalmente na espécie ovina. A mastite estafilocócica corresponde à maior fração nas infecções intramamárias em pequenos ruminantes. O caráter zoonótico de alguns patógenos, a exemplo do Staphylococcus aureus ressalta a importância da implantação de programas de controle em propriedades leiteiras. Algumas das ferramentas de diagnóstico ainda necessitam de padronização, principalmente para espécie caprina que apresenta uma série de particularidades. Ainda são discutidas as principais estratégias de controle como o manejo de fêmeas e suas crias, os procedimentos de ordenha e a utilização de vacinas.

TERMOS DE INDEXAÇÃO: Mastite, caprinos, ovinos, etiologia, epidemiologia, diagnóstico, controle.

\section{INTRODUÇÃO}

A mastite é uma das enfermidades de maior ocorrência em rebanhos leiteiros. A etiologia é ampla, sendo a enfermidade ocasionada primordialmente por micro-organismos (Anderson et al. 2004). Várias são as perdas decorrentes da doença nos rebanhos, principalmente pelo decréscimo acen- 
tuado na produção de leite, gastos com medicamentos, honorários veterinários, além do descarte de animais. Na literatura internacional, diversos artigos tratam de tal enfermidade, sendo o tema amplamente revisado por Bergonier et al. (2003) e Contreras et al. (2007). No entanto, ainda não foram compilados dados acerca desta doença no Brasil. Dessa forma, objetiva-se revisar os conhecimentos acerca da mastite em pequenos ruminantes, com destaque para a etiologia e epidemiologia da doença no Brasil.

\section{MASTITE EM PEQUENOS RUMINANTES: ETIOLOGIA E EPIDEMIOLOGIA}

A prevalência anual da mastite é influenciada por uma série de fatores, relacionados ao animal, patógeno e ao meio ambiente. Levantamentos de pesquisa demonstram que a mastite do tipo subclínica é a que mais predomina nos rebanhos de pequenos ruminantes, cuja prevalência estimada está entre 5-30\%, podendo ser ainda maior. Em contrapartida, a mastite com evidências clínicas apresentase em níveis abaixo de $5 \%$, podendo alcançar maiores taxas em determinadas situações. Contudo, dados a respeito da prevalência da mastite em caprinos e ovinos ainda são escassos (Contreras et al. 2007).

No Brasil, destacam-se as variações dos dados acerca da prevalência da mastite em caprinos e ovinos. Em criações leiteiras, a frequência de mastite subclínica pode oscilar entre $22 \%$ e $75 \%$ (Lima Júnior et al. 1995). Na região Nordeste, sinais clínicos desta enfermidade foram relatados em $51,2 \%$ dos rebanhos (Pinheiro et al. 2000). No estado do Rio Grande do Sul, 30,8\% de metades mamárias avaliadas foram positivas para mamite subclínica (Muricy 2003). A mastite em pequenos ruminantes ocorre durante todo ano, não havendo variação sazonal da doença. Contudo, podemse observar maiores índices de prevalência em proprieda- des com maior produção leiteira ou em períodos chuvosos, em decorrência do aumento no número de vetores (Pinheiro et al. 2000, Albizu \& Baselga 2002).

Os principais micro-organismos isolados de casos de mastite em caprinos e ovinos no Brasil são os Staphylococcus spp. (Mota et al. 2000, Coutinho et al. 2006, Domingues et al. 2006, Langoni et al. 2006, Almeida 2009, Bolsanello et at., 2009) (Quadro 1). Uma das principais características da mastite diz respeito à diversidade de agentes com potencial patogênico. Dentre estes, destacam-se os Staphylococcus coagulase negativa (SCN), que para outras espécies animais são considerados patógenos menores. Têm-se ainda as bactérias do gênero Streptococcus, Corynebacterium, Pseudomonas, Mannheimia haemolytica e algumas espécies de fungos, porém são menos frequentes (Bergonier \& Berthelot 2003, Gonzalo et al. 2004, Contreras et al. 2007). Alguns estudos com infecção experimental vêm demonstrando o potencial patogênico de alguns micro-organismos relevantes, a exemplo do Corynebacterium pseudotuberculosis, que é responsável pelo desencadeamento da enfermidade e pela manifestação de quadros agudos, acompanhados de alterações no leucograma (Pinheiro Junior et al. 2006).

Dentre as espécies de SCN mais prevalentes, tem-se em ordem decrescente de importância: Staphylococcus epidermidis, S. xylosus, S. chromogenes e S. simulans, como as espécies com maior frequência de isolamento em ovelhas. Com relação à espécie caprina, pesquisas demonstram maior ocorrência de $S$. caprae. Entre as espécies de SCN, S. epidermidis está associada, na maioria das vezes, com elevadas contagens de células somáticas (CCS) em ovelhas e cabras, não sendo o mesmo fato observado para o S. caprae (Bergonier et al. 2003). Alguns trabalhos têm demonstrado que a produção de leucotoxinas

Quadro 1. Percentual dos principais micro-organimos isolados de casos de mastite em pequenos ruminantes no Brasil

\begin{tabular}{|c|c|c|c|c|c|c|c|c|}
\hline \multirow[t]{2}{*}{ Micro-organimo } & \multicolumn{4}{|c|}{ Caprina } & \multicolumn{4}{|c|}{ Ovina } \\
\hline & $\begin{array}{l}\text { Mota et al. } \\
(2000)\end{array}$ & $\begin{array}{l}\text { Silva et al. } \\
(2004)\end{array}$ & $\begin{array}{l}\text { Langoni } \\
\text { et al. (2006) }\end{array}$ & $\begin{array}{l}\text { Almeida } \\
(2009)\end{array}$ & $\begin{array}{l}\text { Coutinho } \\
\text { et al.(2006) }\end{array}$ & $\begin{array}{l}\text { Domingues } \\
\text { et al.(2006) }\end{array}$ & $\begin{array}{c}\text { Blagitz } \\
\text { et al.(2008) }\end{array}$ & $\begin{array}{l}\text { Bolsanello } \\
\text { et al.(2009) }\end{array}$ \\
\hline Staphylococcus spp. & 76,3 & 10,0 & - & 73,3 & - & - & - & - \\
\hline $\mathrm{SCN}^{\mathrm{a}}$ & - & 60,0 & - & - & 57,6 & 67,9 & 100,0 & 61,1 \\
\hline S. warneri & - & 12,8 & - & - & - & - & - & - \\
\hline S. caprae & - & 10,0 & - & - & - & - & - & - \\
\hline S. sciuri & - & 7,1 & - & - & - & - & - & - \\
\hline S. epidermidis & - & - & 50,0 & - & - & - & - & - \\
\hline S. aureus & - & 40,0 & 11,4 & - & 15,2 & 9,4 & - & - \\
\hline Streptococcus spp. & 1,7 & - & - & 5,9 & 15,2 & 13,2 & - & 16,6 \\
\hline S. agalactiae & - & - & 13,6 & - & 3,0 & - & - & - \\
\hline Micrococcus spp. & - & - & - & - & 12,0 & - & - & - \\
\hline Corynebacterium spp. & 1,7 & - & - & - & - & 5,7 & - & 5,5 \\
\hline Corynebacterium bovis & - & - & 8,6 & - & - & - & - & - \\
\hline Bacillus spp. & 3,4 & & 2,8 & - & - & - & - & 13,8 \\
\hline Pasteurella multocida & - & - & 4,6 & & - & - & - & - \\
\hline Pseudomonas spp. & - & - & - & 2,9 & - & - & - & - \\
\hline Escherichia coli & - & - & 1,8 & 1,9 & - & - & - & - \\
\hline Klebsiella spp. & - & - & - & 1,9 & - & - & - & - \\
\hline Serratia spp. & 1,7 & & - & - & - & - & - & 2,7 \\
\hline
\end{tabular}


por SCN é nula ou ocorre em pouca quantidade, ao contrário de $S$. aureus que produz várias leucotoxinas. Segundo Rainard et al. (2003), S. aureus obtidos de caprinos e ovinos são mais leucotóxicos que aqueles obtidos de bovinos. Entretanto, estes mesmos autores observaram que os leucócitos polimorfonucleares dos pequenos ruminantes são mais resistentes aos efeitos leucotóxicos quando comparados aos dos bovinos.

O isolamento de SCN geralmente está associado à ausência de sinais clínicos evidentes. Contudo, podem causar infecções persistentes, as quais resultam em maiores CSS, tendo como principal conseqüência a diminuição da qualidade do leite. Além disso, o surgimento da resistência antimicrobiana é mais comum entre as espécies de SCN, que também podem causar injúrias ao tecido mamário ocasionando queda da produção de leite (Taponen \& Pyörälä 2009). Embora os SCN sejam considerados patógenos maiores da mastite em pequenos ruminantes, os mecanismos de patogenicidade nos quadros subclínicos da enfermidade ainda são desconhecidos (Contreras et al. 2007). Recentemente, Leitner et al. (2009) relataram a ocorrência de um surto de mastite subclínica por SCN atípico, enfatizando a necessidade do desenvolvimento de técnicas moleculares para rápida identificação destes patógenos, objetivando facilitar o seu controle. O uso de técnicas moleculares para identificação de SCN é sugerido também por Pyörälä \& Taponen (2009), visto que os métodos fenotípicos não são suficientemente confiáveis.

Alguns trabalhos evidenciam maior incidência de $S$. aureus em rebanhos de cabras leiteiras em contraste com a presença dos SCN. Nestes casos, têm-se quadros mais severos de mastite (Ameh \& Tari 2000). Santos et al. (2007) estudaram os aspectos clínicos e características do leite de ovelhas com mastite induzida experimentalmente com a inoculação de $S$. aureus, sendo observado um quadro de mastite com evolução aguda dos sintomas em todas as ovelhas, sendo o tratamento empregado (antimicrobiano intramamário e sistêmico, além de anti-inflamatório não esteroide) eficiente na recuperação dos animais. Contudo, o dano causado às glândulas mamárias não foi revertido. $S$. aureus destaca-se como agente causador da mastite do tipo contagiosa, sendo seu tratamento difícil devido à elevada resistência (Fagundes \& Oliveira 2004).

$O$ leite e seus derivados desempenham um papel nutricional importante para o homem. A qualidade do leite assume destacada importância sob o ponto de vista da Saúde Pública, pois, embora não existam estatísticas disponíveis sobre o assunto, são frequentes os casos de doenças associadas ao consumo de leite cru ou de derivados produzidos com leite contaminado com micro-organismos patogênicos (Fagundes \& Oliveira 2004). É evidente a importância de $S$. aureus para a saúde pública, principalmente no que se refere às suas exotoxinas. Vários trabaIhos foram realizados sobre este micro-organismo, contudo outros estudos são necessários para se compreender melhor o envolvimento desta bactéria na etiologia de doenças que acometem humanos e animais, desde o tecido cutâneo até infecções sistêmicas (Fagundes \& Oliveira 2004, Freitas et al. 2004).

A produção de enterotoxinas não está restrita à espécie $S$. aureus, visto que alguns estudos têm evidenciado espécies de SCN com potencial para produção de toxinas em condições laboratoriais, tais como: S. xylosus, S. haemolyticus, S. epidermidis, S. cohnii, S. chromogenes, $S$. warneri, S. sciuri e S. lentus (Pereira et al. 2001). No que se refere à possibilidade de eliminação das toxinas estafilocócicas dos alimentos contaminados, não existem dados que atestem a inativação eficiente das mesmas por meio dos processos usuais de pasteurização ou esterilização industrial do leite e derivados. Sendo assim, a presença de $S$. aureus no leite constitui um sério problema de saúde pública (Fagundes \& Oliveira 2004).

Silva et al. (2005a) observaram a produção de hemolisinas por bactérias do gênero Staphylococcus isoladas de casos de mastite em rebanhos de caprinos leiteiros no Brasil, do total de isolados analisados, $80 \%$ demonstraram atividade hemolítica. Entre os SCN obtidos, $65,2 \%$ produziram alfa-hemolisina, $19 \%$ beta-hemolisina e $83,3 \%$ deltahemolisina de forma isolada ou combinada. Todas as espécies de $S$. aureus apresentaram atividade hemolítica para todos os tipos de hemolisinas pesquisadas de forma isolada ou combinada. Estes autores observaram ainda, que a glândula mamária de cabras constitui um reservatório em potencial para Staphylococcus spp. hemolíticos.

No Brasil, os estudos com epidemiologia molecular, envolvendo $S$. aureus isolados de caprinos e ovinos ainda são escassos (Aires-de-Sousa et al. 2007). Estes autores caracterizaram $S$. aureus isolados de casos de mastite subclínica nas espécies bovina, bubalina, caprina e ovina de diferentes municípios do estado do Rio de Janeiro. Estes estudos demonstraram que apenas um clone foi responsável pela maioria dos casos de mastite subclínica em várias regiões do estado do Rio de Janeiro. Além disso, observou-se que este clone não apresenta hospedeiros específicos, tendo a capacidade de colonizar e causar infecção nas diferentes espécies animais.

Estudo visando a detecção de genes codificadores de enterotoxinas A, B e C em isolados de $S$. aureus obtidos de amostras de leite de rebanhos caprino e bovino no Brasil, demonstrou que os isolados de $S$. aureus provenientes do leite de cabras com mastite, tiveram um alto potencial enteropatogênico superior àqueles obtidos de bovinos, além disso, sugere-se que os $S$. aureus produtores de enterotoxinas tipo C são os principais envolvidos na patogenia da mastite em cabras (Silva et al. 2005b).

A freqüência de mastite causada por coliformes varia entre os diferentes países. A mastite causada por Escherichia coli pode ser esporádica e os sinais clínicos podem ser localizados ou resultarem em sintomas clínicos severos com episódios fatais (Santos 2006). Shpigel et al. (2008) sugerem que os isolados de E. coli obtidos de casos de mastite podem formar um novo patótipo - "mammary pathogenic E. coll' (MPEC) em virtude da semelhança entre as cepas obtidas de casos de mastite. 
O desencadeamento da mastite está vinculado à complexa tríade - animal, agente etiológico e meio ambiente. Os fatores determinantes que influenciam na susceptibilidade à mastite incluem: resistência natural da glândula mamária, estágio da lactação, hereditariedade, idade do animal, espécie, infectividade e patogenicidade do agente (Prestes et al. 2002).

Dentre os principais fatores determinantes, destaca-se que no período de lactação há maior susceptibilidade do animal quanto à mastite do tipo contagiosa, enquanto que no período seco, observa-se maior frequência da mastite ambiental (Prestes et al. 2002). A fase de desmame proporciona uma série de mudanças no tecido mamário, dando-se início ao período de involução mamária. No Brasil, estudo de campo demonstrou que o período de involução ativa não representa um período crítico para o surgimento de infecções intramamárias em ovinos Santa Inês (Blagitz et al. 2008), embora o inverso já tenha sido observado (Saratsis et al. 1998).

A agalaxia contagiosa em ovinos e caprinos causa redução abrupta da produção de leite, além de desencadear um aumento significativo da contagem de células somáticas (CCS), sendo considerada uma importante causa de mastite em áreas endêmicas (Corrales et al. 2004). Azevedo et al. (2006) relataram o primeiro surto de agalaxia contagiosa por Mycoplasma agalactiae em pequenos ruminantes no Brasil. O surto aconteceu na região Nordeste, sendo observado um quadro de mastite, agalaxia e poliartrite em cabras, contudo, a origem da doença não foi conhecida. Os autores discutem que a enfermidade foi introduzida no Brasil por meio da importação de animais infectados visando à melhoria dos índices de produção leiteira.

Os lentivírus também são conhecidos como agentes infecciosos para cabras e ovelhas, porém em decorrência do elevado número de animais assintomáticos, estes agentes não são considerados como patógenos clássicos das infecções intramamárias nos pequenos ruminantes (Turin et al. 2005). Birgel Junior et al. (2007) analisaram a influência da infecção pelo vírus da "Caprine arthritis encephalitis" (CAE) nas características físico-químicas e celulares do leite de caprinos, sendo evidenciada uma significativa influência da infecção pelo vírus da CAE na composição do leite, com os valores de eletrocondutividade, teores de cloretos e a CCS, sendo maiores nas cabras infectadas.

Moroni et al. (2005) realizaram um estudo sobre os fatores de risco para as infecções intramamárias em rebanhos de cabras leiteiras, sendo observado que a mastite foi mais frequente entre as fêmeas de terceira e quarta ordem de parto, e quanto ao estágio de lactação, observou-se maior positividade para animais que estavam há vários dias em lactação. Ameh \& Tari (2000), também estudando os fatores predisponentes para mastite caprina, encontraram uma associação positiva entre a mastite e a presença de ferimentos na teta, porém não foram encontradas associações entre o diâmetro da teta, distância entre a teta e o solo e a prevalência de mastite.

\section{TÉCNICAS DE DIAGNÓSTICO DA MASTITE EM PEQUENOS RUMINANTES}

O diagnóstico da mastite pode ser efetuado utilizando-se métodos diretos e indiretos. Os exames diretos baseiamse na identificação do agente etiológico, mediante a demonstração da presença de micro-organismos nas amostras de leite encaminhadas aos laboratórios. Por outro lado, os testes indiretos se fundamentam em vários critérios de evolução de intensidade da reação inflamatória (Mota 2008).

Nas formas agudas e crônicas, o diagnóstico é realizado considerando-se os sinais clínicos, onde no primeiro caso, observa-se o aparecimento súbito de febre $\left(40^{\circ}\right.$ a $\left.42^{\circ} \mathrm{C}\right)$, perda de apetite, apatia, dispnéia e relutância em se locomoverem. Nos casos de mastite gangrenosa, o úbere apresenta coloração azulada e com aspecto edematoso (Anderson et al. 2004, Mota 2008). Contudo, o exame físico não deve ser utilizado como método diagnóstico de forma isolada, sendo imprescindível a associação com outras técnicas diagnósticas, como a lactocultura (Nunes et al. 2008).

A cultura bacteriológica do leite é considerada o teste padrão ouro para o diagnóstico das infecções intramamárias em espécies leiteiras. Vários trabalhos vêm sendo desenvolvidos objetivando alcançar maiores taxas de recuperação de patógenos em amostras de leite contaminadas (Contreras et al. 2007). Com relação à influência do tempo de coleta no diagnóstico bacteriológico de infecções intramamárias, Sánchez et al. (2004) observaram que a especificidade da lactocultura realizada após a ordenha foi de $99,4 \%, 99,9 \%, 100 \%, 99,9 \%$ e $100 \%$ para o isolamento de SCN, bacilos gram-negativos, Streptococcus spp., corinebactérias e culturas mistas, respectivamente, sendo sugerido que a coleta de amostras de leite após a ordenha pode ser um procedimento eficiente para o diagnóstico de infecções intramamárias.

Com relação ao efeito do congelamento, observou-se que esta prática afeta positivamente a recuperação de patógenos em amostras de leite, podendo ser adotada em programas de controle da mastite subclínica caprina, em decorrência do incremento no número de isolamento de Staphylococcus coagulase negativa (Sánchez et al. 2003). Sierra et al. (2006) estudaram o efeito da temperatura sobre a contagem eletrônica de células somáticas, não constatando diferenças nas temperaturas de $40^{\circ} \mathrm{C} \mathrm{e} 60^{\circ} \mathrm{C}$.

Estudo envolvendo análise bacteriológica e hematológica em caprinos com mastite subclínica verificou que os índices eritrocitários de cabras com mastite foram significativamente menores do que aqueles de cabras com a enfermidade (Ajuwape et al. 2005). Por outro lado, estes autores observaram que as contagens totais e diferenças de leucócitos em cabras com mastite foram significativamente maiores do que o observado em fêmeas sem a doença, demonstrando que o hemograma pode auxiliar os clínicos na previsão do prognóstico de animais com mastite.

\footnotetext{
${ }^{5}$ Somacount $300^{\circledR}$, Bentley Instruments Incorporated, Minnesota,
} USA. 
A contagem de células somáticas (CCS) constitui a base das técnicas de diagnóstico indireto das mastites em todas as espécies de ruminantes leiteiros (Mota 2008). Assim, CCS é amplamente utilizada para avaliação do status sanitário da glândula mamária em cabras e ovelhas (McDougall et al. 2001). A maioria das diferenças entre caprinos e ovinos que afetam o diagnóstico da mastite é relatada para CCS. Estas diferenças são, principalmente, em virtude da alta CCS em cabras não infectadas, o alto componente apócrino na secreção do leite e o elevado número de fatores não infecciosos que podem incrementar a contagem de células somáticas em cabras quando comparado com ovelhas (Paape et al. 2001). Vários trabalhos têm sido realizados na tentativa de estabelecer a CCS de cabras não infectadas, mas a comparação dos resultados constitui uma tarefa árdua, em decorrência da quantidade de fatores biológicos e instrumentais que podem interferir neste parâmetro (Andrade et al. 2001).

Os estudos são divergentes quanto à utilização do Somacount $300^{5}$, calibrado para espécie bovina, sendo encontrada tanto correlação positiva com a microscopia direta (Andrade et al. 2001), quanto o inverso, com superestimação da CCS (Zeng 1996).

De forma geral, os testes indiretos necessitam de padronização para a espécie caprina. O Wisconsin Mastitis Test tem subestimado a CCS, necessitando de ajustes para fêmeas caprinas (Andrade et al. 2001). O California Mastitis Test (CMT) é outro método indireto, sendo a prova eleita para o diagnóstico das mastites subclínicas pela facilidade de execução, baixo custo e por permitir um resultado satisfatório acerca da situação da mastite em rebanhos leiteiros (Mota 2008). Em decorrência do maior número de células somáticas no leite de fêmeas caprinas, estudos apontam uma maior confiabilidade do CMT quanto à sua sensibilidade a partir do nível de 2+ (Mota 2008, Almeida 2009).

A utilização da CCS ainda não está bem estabelecida no diagnóstico da mastite caprina. Trabalhos desenvolvidos no Brasil têm mostrado que os valores máximos, mínimos e médios de CCS são bem próximos, sendo encontrados valores elevados de CCS tanto na presença, como ausência de crescimento bacteriano (Quadro 2) (Santos et al. 2004, Vilanova et al. 2008). Silva et al. (2001) estudaram a associação entre o CMT e a CCS objetivando a avaliação da saúde da glândula mamária caprina, sendo observada uma correlação positiva entre estes dois testes. Porém, foram observadas elevadas contagens de células em amostras negativas à lactocultura, denotando que - CMT pode ser usado como teste de triagem no diagnóstico da mastite, porém, devendo-se sempre associá-lo ao exame microbiológico.

Sugere-se que a CCS pode ser utilizada para a detecção da mastite caprina, devendo-se utilizar contagens superiores a $1,0 \times 10^{6}$ células $/ \mathrm{mL}$ de leite como critério para a realização de exames microbiológicos (Paes et al. 2003). Pessoa et al. (1999) estudaram o limiar de células somáticas no leite de cabras em Pernambuco, sendo observada uma alta similaridade entre a cultura positiva e escores $\geq 1.000 .000$ cél. $/ \mathrm{mL}$ na CCS. Estudos realizados no Brasil vêm demonstrando que a variação da CCS no leite de cabras ocorre em função de uma série de fatores, entre eles, o estágio de lactação e ordem de parto, época do ano e tipo de ordenha.

Os estágios finais da lactação e fêmeas com maior número de parições são situações que determinam contagens mais elevadas, devendo-se ter cautela durante a avaliação da saúde da glândula mamária nestes casos (Souza et al. 2009).

Leitner et al. (2008) avaliaram as perdas de rendimento de leite de cabras e ovelhas com infecção intramamária e sua relação com a CCS, sendo sugerida a seguinte classificação: Alta qualidade do leite $<800.000 \mathrm{CCS} / \mathrm{mL}$, associada com infecção de aproximadamente $25 \%$; Média qualidade do leite $<1.500 .000 \mathrm{CCS} / \mathrm{mL}$, associada com infecção entre 25 e 50\%; Baixa qualidade do leite $>1.500 .000$ $\mathrm{CCS} / \mathrm{mL}$, associada com taxa de infecção acima de $50 \%$.

Além destes métodos, tem-se a disposição outras ferramentas como: análise das variações da composição do leite, que se baseia na medição dos íons mediante condutividade elétrica e outros parâmetros como lactose, análise de proteínas séricas e pesquisa de enzimas específicas indicadoras de lesão do tecido mamário (Mota 2008). Quanto aos principais indicadores inflamatórios utilizados no diagnóstico da mastite ovina, têm-se maiores valores preditivos para a CCS, CMT e teor de cloreto. Por outro lado, o pH, o teor de lactose e o índice cloreto-lactose apresentam-se como marcadores inflamatórios menos sensíveis (Nunes et al., 2008).

\section{Quadro 2. Sensibilidade e/ou limiar de células somáticas de alguns métodos indiretos empregados no diagnóstico da mastite subclínica em caprinos criados em regiões do Brasil}

\begin{tabular}{lccccc}
\hline Método & $\begin{array}{c}\text { Santos et al. } \\
(1995)\end{array}$ & $\begin{array}{c}\text { Pessoa et al. } \\
(1999)\end{array}$ & $\begin{array}{c}\text { Paes et al. } \\
(2003)\end{array}$ & $\begin{array}{c}\text { Santos et al. } \\
(2004)\end{array}$ & $\begin{array}{c}\text { Tonin \& Nader } \\
\text { Filho (2005) }\end{array}$ \\
\hline CMT (Sea ${ }^{a}$ & & & & & \\
Traços & - & - & - & - & 57,6 \\
$1+$ & 73,52 & - & - & - & 48,5 \\
$2+$ & 70,58 & - & - & 59,2 & 37,9 \\
$3+$ & 24,24 & - & - & - & 27,3 \\
CCS (Limiar - cél/mL) & - & $\geq 1.000 .000$ & $\geq 1.000 .000$ & $\geq 500.000$ & \\
a Sensibilidade. & & & & &
\end{tabular}




\section{ESTRATÉGIAS DE CONTROLE E PREVENÇÃO}

A higiene durante a ordenha constitui a base para o sucesso de um programa de controle das mastites em pequenos ruminantes. O manejo higiênico-sanitário voltado para prevenção da mastite engloba atenção especial ao ordenhador, ao animal, à ordenhadeira e ao meio ambiente. O sucesso do tratamento da mastite envolve uma série de fatores incluindo a escolha do antimicrobiano, susceptibilidade do micro-organismo, duração do tratamento, dosagem empregada e o status imune do animal (Anderson et al. 2004, Mota 2008).

Em pequenos ruminantes, a terapia no período seco não constitui uma prática rotineira nas criações voltadas para produção de leite. Contudo, a terapia da mastite em ovelhas e cabras não-lactantes tem-se mostrado como uma ferramenta eficiente na redução das infecções intramamárias, proporcionando ganhos na produção de leite (Chaffer et al. 2003, Gonzalo et al. 2004). Neste sentido, o tratamento no período seco deverá ser recomendado para rebanhos com um elevado número de animais com mastite subclínica associado com altas CCS. O manejo adequado do rebanho, especialmente antes do parto e nos dias que se seguem, resulta em menores índices de mastite, sem a necessidade de utilização dos antimicrobianos (Shwimmer et al. 2008).

Diferentemente das infecções por Staphylococcus aureus, outras infecções estafilocócicas são mais facilmente tratadas e eliminadas. Entretanto, tem-se observado o fenômeno da resistência antimicrobiana em muitos isolados de Staphylococcus coagulase negativa (Lollai et al. 2008, Taponen \& Pyörälä 2009).

O uso de vacinas para o controle da mastite torna-se uma opção econômica para os veterinários e criadores, uma vez que reduz custos e tem efeitos positivos sobre a qualidade do leite e a saúde pública, já que diminui a necessidade do uso de antimicrobianos (Portes et al. 2006). Vacinas contra mastite clínica gangrenosa, que estão disponíveis no mercado de pequenos ruminantes, são amplamente usadas quando há uma alta prevalência da infecção. Contudo, devido os diferentes relatos sobre a efetividade destas vacinas para vacas leiteiras e ovelhas, e sua inabilidade para prevenir novas infecções, tem sido sugerido que as vacinas sejam usadas em rebanhos leiteiros com alta prevalência de $S$. aureus para reduzir os sinais clínicos (Contreras et al. 2007). A efetividade dos programas de vacinação contra mastite causada por $S$. aureus tem sido relatada para ovelhas, mas não para cabras (Amorena et al. 1994, Tollersrud et al. 2002). Atualmente, estudos sobre a vacinação têm fracassado em ratificar esta técnica como uma ferramenta para o controle da mastite em pequenos ruminantes, sendo estudos sobre imunização, particularmente envolvendo a caracterização dos mecanismos imunológicos de resposta ainda necessários para aprimorar esta estratégia (Contreras et al. 2007). Coelho et al. (2008) observaram uma redução no número de casos de mastite em cabras leiteiras, a partir da antibioticoterapia associada ao uso de vacina contra mastite estafilocócica.
Poucas drogas são especificamente licenciadas para uso em pequenos ruminantes, particularmente em cabras. $O$ uso de antibióticos ou outras drogas de bovinos em pequenos ruminantes, ou até mesmo o uso de produtos em caprinos de produtos indicados para ovinos, constituem um alto risco devido à segurança e eficácia destes produtos em cada espécie serem em grande parte desconhecidos (Mavrogianni et al. 2004). Alguns trabalhos realizados no Brasil vêm demonstrando a presença de sensibilidade entre os diferentes patógenos isolados de casos de mastite em caprinos e ovinos (Silva et al. 2004, Coutinho et al. 2006, Almeida 2009), principalmente para a gentamicina (Mota et al. 2000, Langoni et al. 2006, Domingues et al. 2006).

O tratamento com antibióticos deverá sempre ser acompanhado por um veterinário, no sentido de garantir a adequada e higiênica administração (Contreras et al. 2007). O uso excessivo de antibióticos pode aumentar o risco da resistência a estes medicamentos, fato que tem se tornado um problema de saúde pública. Goni et al. (2004) destacam que a detecção de cepas de $S$. aureus resistentes aos aminoglicosídeos deve ser considerada uma preocupação para saúde pública, dado ao mecanismo similar para cepas isoladas em humanos. Recentemente, Soares et al. (2008) demonstraram que isolados clínicos de SCN provenientes de amostras coletadas de animais e humanos têm apresentado elevada resistência à penicilina e à ampicilina.

A desinfecção da teta tem sido demonstrada como altamente eficaz na prevenção de novas infecções intramamárias em vacas por diferentes patógenos, especialmente SCN (Mota 2008). Em pequenos ruminantes, a desinfecção da teta após a ordenha tem sido usada, principalmente, em rebanhos altamente infectados (Paape et al. 2001, Bergonier \& Berthelot 2003, Contreras et al. 2003), e esta tem se revelado como método muito eficaz para prevenir a mastite em pequenos ruminantes.

Os programas de controle implantados em fazendas de bovinos leiteiros não podem ser diretamente aplicados em fazendas de criação de pequenos ruminantes. Este fato ocorre devido às diferenças de tamanho dos rebanhos, uso de áreas marginais para criação destes animais, baixa renda dos produtores, o sistema particular de pastoreio, e outras particularidades fazem dos pequenos ruminantes espécies distintas dos bovinos leiteiros e requerem a designação de estratégias específicas para o controle da qualidade do leite (Contreras et al. 2007).

As ovelhas Santa Inês, diferentemente de outras raças especializadas para corte, apresentam longo período de lactação, aumentando a propensão na ocorrência da mastite (Melo et al. 2008). Estes autores avaliaram uma metodologia profilática contra a mastite clínica em ovelhas da raça Santa Inês, sendo observado que a utilização de antibióticos no momento do desmame e da secagem diminuiu a freqüência de aparecimento dos sinais da mastite clínica.

A forma e a ordem com que as fêmeas são levadas até a sala de ordenha repercutem de forma significativa sobre a saúde da glândula mamária de todo rebanho. A utilização da linha de ordenha e realização de inspeções diárias das glândulas 
mamárias e dos equipamentos de ordenha constituem práticas de manejo de grande relevância dentro de programas de controle da mastite em pequenos ruminantes (Mota 2008).

Da mesma forma, a situação epidemiológica de $S$. aureus em fêmeas lactantes é de difícil controle, pois os cordeiros ou cabritos infectados pelas mães podem transmitir a doença para outras fêmeas. Quanto às infecções por Mannheimia haemolytica, cordeiros constituem a principal fonte de disseminação da infecção. A utilização de colostro pasteurizado tem aumentado em criações modernas por razões produtivas e sanitárias, como o combate a infecção pelos lentivírus (Contreras et al. 2004), sendo um prática de manejo que melhora o status sanitário de cordeiros e cabritos e ao úbere de suas mães, visto que permite a remoção das crias ao parto e o fornecimento de colostro e leite livre de patógenos (Contreras et al. 2007).

A suplementação com vitamina $E$ é importante para a manutenção de alguns dos principais mecanismos de defesa animal, incluindo a produção de anticorpos, a proliferação celular, a produção de citocinas, o metabolismo da prostaglandina e as funções dos neutrófilos (Hogan et al. 1993). Estudo realizado por Paes et al. (2003) demonstrou que a CCS e o número de S.aureus são menores nos caprinos suplementados com vitamina $\mathrm{E}$.

A utilização de medicamentos homeopáticos e fitoterápicos tem demonstrado resultados satisfatórios durante a terapia dos casos de mastite, porém os estudos são voltados em sua maioria para espécies bovina (Almeida 2004, Thomaz 2004). Mitidiero (2002) demonstrou que esta terapia alternativa permite manter a sanidade do rebanho em padrões semelhantes aos da alopatia, constituindo-se assim, em uma opção viável para os produtores de leite. Estudos in vitro visando à determinação do potencial antimicrobiano de plantas pertencentes à flora brasileira têm demonstrando resultados satisfatórios (Granato et al. 2005, Oliveira et al. 2007, Ushimaru et al. 2007), porém observase a descontinuidade destes estudos e uma fragmentação dos resultados, não permitindo muitos avanços na área.

\section{CONCLUSÕES}

Observa-se que dentre os principais patógenos da mastite em pequenos ruminantes, destaca-se o gênero Staphylococcus, nos diferentes sistemas de criação. Além disso, os dados acerca da prevalência da enfermidade apresentam ampla variação, estando na dependência de uma série de fatores, dentre estes, estão aqueles ligados à região. Quanto ao diagnóstico tem-se uma discordância nos limites indicativos da presença da infecção, o que sugere ser este um vasto campo de pesquisa na tentativa de determinar os padrões limites da CCS, principalmente na espécie caprina.

No Brasil, tem-se observado um aumento no número de criações destinadas a produção de leite, especialmente a caprinocultura leiteira, sendo de fundamental importância a realização de estudos direcionados para os aspectos etiológicos, epidemiológicos e de diagnóstico da mastite caprina e ovina, visando fornecer subsídios para a elaboração de programas de controle e profilaxia da enfermidade e, desta forma, minimizar os prejuízos econômicos resultantes da presença da enfermidade. Além disso, considerando o baixo custo da fitoterapia, tornam-se necessários estudos acerca da atividade in vitro do extratos de plantas.

\section{REFERÊNCIAS}

Aires-de-Sousa M., Parente C.E.S.R., Vieira-da-Motta O., Bonna I.C.F., Silva D.A. \& Lencastre H. 2007. Characterization of Staphylococcus aureus isolates from buffalo, bovine, ovine, and caprine milk samples collected in Rio de Janeiro State, Brazil. Appl. Environ. Microbiol. 73(12):3845-3849.

Ajuwape A.T.P., Roberts A.A., Solarin O.O. \& Adetosoye A.I. 2005. Bacteriological and haematological studies of clinical mastitis in goats in Ibadan, OYO State, Nigeria. Small Rumin. Res. 60:307-310.

Albizu I. \& Baselga R. 2002. Sheep and goat mastitis: Seasonal variation in aetiology. Albeitar 53:28.

Almeida J.F. 2009. Agentes infecciosos causadores de mastite e parâmetros físico-químicos na qualidade do leite de cabra in natura. Tese de Doutorado em Higiene Veterinária e Processamento Tecnológico de Produtos de Origem Animal, Faculdade de Veterinária, Universidade Federal Fluminense, Rio de Janeiro, RJ. 106p.

Almeida L.A.B. 2004. Avaliação do tratamento alopático e homeopático de mastite bovina em animais inoculados com Staphylococcus aureus. Dissertação de Mestrado em epidemiologia experimental e aplicada às zoonoses, Faculdade de Medicina Veterinária e Zootecnia, USP, São Paulo, SP. 104p.

Ameh M.J.A. \& Tari I.S. 2000. Observations on the prevalence of caprine mastitis in relation to predisposing factors in Maiduguri. Small Rumin. Res. 35:1-5.

Amorena B., Baselga R. \& Albizu I. 1994. Use of liposome-immuno potentiated exopolysaccharide as a component of an ovine mastitis staphylococcal vaccine. Vaccine 12:243-249.

Anderson D.E., Hull B.H., Pugh D.G. 2004. Enfermidades da glândula mamária, p.379-399. In: Pugh D.G. (Eds), Clínica de Ovinos e Caprinos. Roca, São Paulo.

Andrade P.V.D., Souza M.R., Borges I. \& Penna C.F.A.M. 2001. Contagem de células somáticas em leite de cabra. Arq. Bras. Med. Vet. Zootec. 53(3):396-400.

Azevedo E.O., Alcântara M.D.B., Nascimento E.R., Tabosa I.M., Barreto M.L., Almeida J.F., Araújo M.O., Rodrigues A.R.O., RietCorrea F. \& Castro R.S. 2006. Contagious agalactia by Mycoplasma agalactiae in small ruminants in Brazil: First report. Braz. J. Microbiol. 37:576-581.

Bergonier D. \& Berthelot X. 2003. New advances in epizootiology and control of ewe mastitis. Livest. Prod. Sci. 79:1-16.

Bergonier D., De Crémoux R., Rupp R., Lagriffoul G. \& Berthelot X. 2003. Mastitis of dairy small ruminants. Vet. Res. 34:689-716.

Birgel Junior E.H., Cestari V., Sampaio R.M., Lara M.C.C.S.H., Birgel D.B., Raimondo R.F.S. Brandespin F.B. \& Birgel E.H. 2007. Influência da infecção pelo vírus da artrite encefalite caprina nas características físico-químicas e celulares do leite de caprinos. Arqs Inst. Biológico, São Paulo, 74(3):199-206.

Blagitz M.G., Batista C.F., Souza F.N., Benites N.R., Melville P.A., Stricagnolo C.R., Ricciardi M., Gomes V., Azevedo M.R., Sanches B.G.S. \& Della Libera A.M.M.P. 2008. Perfil celeular e microbiológico do leite de ovelhas Santa Inês no período lactante e pós-desmame. Pesq. Vet. Bras. 28(9):417-422.

Bolsanello R.X., Hartman M., Domingues P.F., Mello Júnior A.Z. \& Langoni H. 2009. Etiologia da mastite em ovelhas Bergamácia submetidas à ordenha mecânica, criadas em propriedade de Botucatu, SP. Vet. Zootec. 16(1):221-227.

Chaffer M., Leitner G., Zamir S., Winkler M., Glickman A., Ziv N. \& Saran A. 2003. Efficacy of dry-off treatment in sheep. Small Rumin. Res. 47:11-16. 
Coelho A.J.C., Peixoto R.M., Andrade N.P.C., Nogueira D.M., Krewer C.C., Alencar P.H.P. \& Costa M.M. 2008. Eficácia de três métodos empregados no controle da mastite estafilocócica em cabras leiteiras criadas no município de Santa Maria da Boa Vista, PE. Anais V Congresso Nordestino de Produção Animal, Aracaju, SE. (Resumo)

Contreras A., Luengo C., Sanchez A. \& Corrales J.C. 2003. The role of intramammary pathogens in dairy goats. Livest. Prod. Sci. 79:273-283.

Contreras A., Sanchez A. \& Corrales J. 2004. Health priorities in dairy goats, p.229-243. In: Daza A., Fernández C. \& Sánchez A. (Eds), Goat Livestock: Production, Nutrition and Health. Agrícola Espanola, España.

Contreras A., Sierra D., Sánchez A., Corrales J.C., Marco J.C., Paape M.J. \& Gonzalo C. 2007. Mastitis in small ruminants. Small Rumin. Res. 68:145-153.

Corrales J.C., Sanchez A., Luengo C., Poveda J.B. \& Contreras A. 2004. Effect of clinical contagious agalactia on the bulk tank milk somatic cell count in Murciano-Granadina goat herds. J. Dairy Sci. 87:3165-3171.

Coutinho D.A., Costa J.N., Ribeiro M.G. \& Torres J.A. 2006. Etiologia e sensibilidade antimicrobiana in vitro de bactérias isoladas de oveIhas da raça Santa Inês com mastite subclínica. Revta Bras. Saúde Prod. Anim. 7(2):139-151.

Domingues P.F., Lucheis S.B., Serrão L.S., Fernandes L.S., Contente A.P.A., Martins E.C.V. \& Langoni H. 2006. Etiologia e sensibilidade bacteriana da mastite subclínica em ovelhas da raça Santa Inês. Ars Vet. 22(2):146-152.

Fagundes H. \& Oliveira C.A.F. 2004. Infecções intramamárias causadas por Staphylococcus aureus e suas implicações em saúde pública. Ciência Rural 34(4):1315-1320.

Freitas M.F.L., Leal Balbino T.C., Mota R.A. \& Stamford T.L.M. 2004. Exotoxinas estafilocócicas. Ciênc. Vet. Tróp. 7(2/3):63-74.

Goni P.,Vergara Y., Ruiz J., Albizu I., Vila J. \& Gomez-Lus R. 2004. Antibiotic resistance and epidemiological typing of Staphylococcus aureus strains from ovine and rabbit mastitis. Int. J. Antimicrob. Agents 23:268-272.

Gonzalo C., Tardáguila J.A., De La Fuente L.F. \& San Primitivo F. 2004. Effects of selective and complete dry therapy on prevalence of intramammary infection and on milk yield in the subsequent lactation in dairy ewes. J. Dairy Res. 71:33-38.

Granato D., Nunes D.S., Mattos P.P., Rios E.M., Glinski A., Rodrigues L.C. \& Zanusso Júnior G. 2005. Chemical and biological evaluation of rejects from the wood industry. Braz. Arch. Biol. Technol. 48:237241.

Hogan J.S., Weiss W.P. \& Smith K.L. 1993. Role of vitamin E and selenium in host defense against mastitis. J. Dairy Sci. 76:27952803.

Langoni H., Domingues P.F. \& Baldini S. 2006. Mastite caprina: seus agentes e sensibilidade frente a antimicrobianos. Revta Bras. Ciênc. Vet. 13(1):51-54.

Leitner G., Silanikove N. \& Merin U. 2008. Estimate of milk and curd yield loss of sheep and goats with intrammamary infection and its relation to somatic cell count. Small Rumin. Res. 74:221-225.

Leitner G., Sela S., Hammer-Muntz O., Zivotofsky D., Weisblit L., Chaffer M. \& Zamir S. 2009. Outbreak of subclinical mastitis in a flock of dairy goats associated with atypical Staphylococcus haemolyticus. J. Dairy Res. 76:1-5.

Lima Júnior A.D., Nader Filho A. \& Vianni M.C.E. 1995. Fatores condicionantes da mastite subclínica caprina em criatórios do Rio de Janeiro. Arq. Bras. Med. Vet. Zootec. 47(4):463-474.

Lollai S.A., Ziccheddu M., Maurob C.D., Manunta D., Nuddab A. \& Leori G. 2008. Profile and evolution of antimicrobial resistence of ovine mastitis pathogens. Small Rumin. Res. 74:249-254.

Mavrogianni V.S., Alexopoulos C. \& Fthenakis G.C. 2004. Field evaluation of flunixin meglumine in the supportive treatment of caprine mastitis. J. Vet. Pharmacol. Ther. 27:373-375.

McDougall S., Murdough P., Pankey W., Delaney C., Barlow J. \& Scruton D. 2001. Relationships among somatic cell count, California mastitis test, impedance and bacteriological status of milk in goats and sheep in early lactation. Small Rumin. Res. 40:245-254.

Melo C.B., Almeida B.M., Oliveira A.A., Azevedo H.C., Melo L.S.S. \& Mata S.S. 2008. Avaliação de uma metodologia profilática contra a mastite clínica em ovelhas da raça Santa Inês. Arq. Bras. Med. Vet. Zootec. 60(4):1011-1013.

Mitidiero A.M.A. 2002. Potencial do uso de homeopatia, bioterápicos e fitoterapia como opção na bovinocultura de leite: avaliação dos aspectos sanitários e de produção. Dissertação de Mestrado em Agroecossistemas, Centro de Ciências Agrárias, Universidade Federal de Santa Catarina, Florianópolis, SC. 119p.

Moroni P., Pisoni G., Ruffo G. \& Boettcher P.J. 2005. Risk factors for intramammary infections and relationship with somatic-cell counts in Italian dairy goats. Prev. Vet. Med. 69:163-173.

Mota R.A. 2008. Aspectos epidemiológicos, diagnóstico e controle das mastites em caprinos e ovinos. Tecnol. Ciênc. Agropec. 2(3): 57-61.

Mota R.A., De Castro F.J.C., Da Silva L.B.G. \& Oliveira A.A.F. 2000. Etiologia e sensibilidade a antimicrobianos in vitro das bactérias isoladas do leite de cabras com mastite procedentes da Região Metropolitana do Recife, Pernambuco, Brasil. Hora Vet. 19(114)26-29.

Muricy R.F. 2003. Ocorrência de mamite subclínica em caprinos e qualidade higiênicosanitária do leite produzido em propriedades associadas à Cooperativa Languiru, Teutônia, RS. Dissertação de Mestrado em Ciências Veterinárias, Faculdade de Veterinária, Universidade Federal do Rio Grande do Sul, Porto Alegre, RS. 83p.

Nunes G.R., Blagitz M.G., Freitas C.B., Souza F.N., Ricciardi M., Stricagnolo C.R., Sanches B.G.S., Azedo M.R., Sucupira M.C.A. \& Della Libera AM.M.P. 2008. Avaliação de indicadores inflamatórios no diagnóstico da mamite ovina. Arqs Inst. Biológico, São Paulo, 75(3):271-278.

Oliveira D.F., Pereira A.C., Figueiredo H.C.P., Carvalho D.A., Silva G., Nunes A.S., Alves D.S. \& Carvalho H.W.P. 2007. Antibacterial activity of plant extracts from Brazilian southeast region. Fitoterapia 78:142-145.

Paape M.J., Poutrel B., Contreras A., Marco J.C. \& Capuco A.V. 2001. Milk somatic cells and lactation in small ruminants. J. Dairy Sci. 84:237-244.

Paes P.R.O., Lopes S.T.A., Lopes R.S., Kohayagawa A., Takahira R.K. \& Langoni H. 2003. Efeitos da administração de vitamina $E$ na infecção mamária e na contagem de células somáticas de cabras primíparas desafiadas experimentalmente com Staphylococcus aureus. Arq. Bras. Med. Vet. Zootec. 55(1):15-20.

Pereira M.L., Carmo L.S. \& Pereira J.L. 2001. Comportamento de estafilococos coagulase negativos pauciprodutores de enterotoxinas em alimentos experimentalmente inoculados. Ciênc. Tecnol. Aliment. 21:171-175.

Pessoa A.L.P., Lima Junior A.D. \& Mota R.A. 1999. Estudo do limiar de células somáticas no leite de cabras na região metropolitana de Recife e agreste de Pernambuco. Ciênc. Vet. Trop. 2(2):100-107.

Pinheiro R.R., Gouveia A.M.G., Alves F.S.F. \& Haddad J.P.A. 2000. Aspectos epidemiológicos da caprinocultura cearense. Arq. Bras. Med. Vet. Zootec. 52(5):534-543.

Pinheiro Junior J.W., Oliveira A.A.F., Alves F.S.F., Silva L.B.G., Rabelo S.S.A. \& Mota R.A. 2006. Corynebacterium pseudotuberculosis experimental infection of goats mammary gland. Arqs Inst. Biológico, São Paulo, 73(4):395-400.

Portes V.M., Wolff C., Vaz A.K. \& Dick W. 2006. Efeito da vacinação contra a mastite estafilocócica sobre a associação de Staphylococcus spp. a células do leite. Acta Scient. Vet. 34(2):137-141. 
Prestes D.S., Filappi A. \& Cecim M. 2002. Susceptibilidade à mastite: fatores que a influenciam - uma revisão. Revta FZVA 9(1):118-132.

Pyörälä S. \& Taponen S. 2009. Coagulase-negative staphylococci: Emerging mastitis pathogens. Vet. Microbiol. 134:3-8.

Rainard P., Corrales J.C., Barrio M.B., Cochard T. \& Poutrel B. 2003. Leucotoxic activities of Staphylococcus aureus strains isolated from cows, ewes, and goats with mastitis: Importance of LukM/LukF'-PV leukotoxin. Clin. Diagn. Lab. Immunol. 10:272-277.

Sánchez A., Contreras A., Jiménez J., Luengo C., Corrales J.C. \& Fernández C. 2003. Effect of freezing goat milk samples on recovery of intramammary bacterial pathogens. Vet. Microbiol. 94:71-77.

Sánchez A., Contreras A., Corrales J.C. \& Muñoz P. 2004. Influence of sampling time on bacteriological diagnosis of goat intramammary infection. Vet. Microbiol. 98:329-332.

Santos L.F.L., Castro R.S. \& Costa E.O. 1995. "California Mastitis Test" e "Whiteside modificado" como triagem para mastite caprina. Pesq. Agropec. Bras. 30(2):295-298.

Santos A.R., Scherer S. \& Schmidt V. 2004. Validação da contagem de células somáticas e do California Mastitis Test como método de diagnóstico da mamite subclínica em caprinos. Revta Ciênc. Agrovet. 3(1):50-55.

Santos C.D.M. 2006. Staphylococcus sp. e enterobactérias isoladas de mastite recorrente em oito rebanhos da região de UberlândiaMG: perfil de susceptilidade aos antimicrobianos. Dissertação de Mestrado em Ciências Veterinárias, Universidade Federal de Uberlândia, Uberlândia, MG. 54p.

Santos R.A., Mendonça C.L., Afonso J.A.B. \& Simão L.C.V. 2007. Aspectos clínicos e características do leite em ovelhas com mastite induzida experimentalmente com Staphylococcus aureus. Pesq. Vet. Bras. 27(1):6-12.

Saratsis P., Leontides L., Tzora A., Alexopoulos C. \& Fthenakis G.C. 1998. Incidence risk and aetiology of mammary abnormalities in dry ewes in flocks in Southern Greece. Prev. Vet. Med. 37:173-183.

Shpigel N.Y., Elazar S. \& Rosenshine I. 2008. Mammary pathogenic Escherichia coli. Curr. Opin. Microbiol. 11:60-65.

Shwimmer A., Kenigswald G., Van Straten M., Lavic Y., Merin U., Weisblit L. \& Leitner G. 2008. Dry-off treatment of Assaf sheep: Efficacy as a management tool for improving milk quantity and quality. Small Rumin. Res. 74:45-51.

Sierra D., Sánchez A., Luengoa C., Corrales J.C., Moralesa C.T., Contreras A. \& Gonzalo C. 2006. Temperature effects on fossomatic cell counts in goats milk. Int. Dairy J. 16:385-387.

Silva E.R., Araújo A.M., Alves F.S.F., Pinheiro R.R. \& Saukas T.N. 2001. Associação entre o California Mastitis Test e a Contagem de Células Somáticas na avaliação da saúde da glândula mamária caprina. Braz. J. Vet. Res. Anim. Sci. 38:46-48.

Silva E.R., Siqueira A.P., Martins J.C.D., Ferreira W.P.B. \& Silva N.
2004. Identification and in vitro antimicrobial susceptibility of Staphylococcus species isolated from goat mastitis in the Northeast of Brazil. Small Rumin. Res. 55:45-49.

Silva E.R., Boechat J.U.D., Martins J.C.D, Ferreira W.P.B, Siqueira A.P. \& Silva N. 2005a. Hemolysin production by Staphylococcus aureus species isolated from mastitic goat milk in Brazilian dairy herds. Small Rumin. Res. 56:271-275.

Silva E.R., Carmo L.S. \& Silva N. 2005b. Detection of the enterotoxins A, B, and C genes in Staphylococcus aureus from goat and bovine mastitis in Brazilian dairy herds. Vet. Microbiol. 106:103-107.

Soares L.C., Pereira I.A., Coelho S.M.O., Cunha C.M.M, Oliveira D.F.B., Miranda A.N. \& Souza M.M.S. 2008. Caracterização fenotípica da resistência a antimicrobianos e detecção do gene mecA em Staphylococcus spp. coagulase-negativos isolados de amostras animais e humanas. Ciênc. Rural 38(5): 1346-1350.

Souza G.N., Brito J.R.F., Brito M.A.V.P., Lange C., Faria C.G., Moraes L.C.D., Fonseca R.G. \& Silva Y.A. 2009. Composition and bulk tank somatic cell counts of milk from dairy goat herds in southeastern Brazil. Braz. J. Vet. Res. Anim. Sci. 46(1):19-24.

Taponen S. \& Pyörälä S. 2009. Coagulase-negative staphylococci as cause of bovine mastitis: Not so different from Staphylococcus aureus? Vet. Microbiol. 134:29-36.

Thomaz L.W. 2004. Efeito da utilização de medicamentos no tratamento da mastite subclínica em vacas leiteiras. Dissertação de Mestrado em Sanidade Animal, Escola de Veterinária, Universidade Federal de Goiás, Goiânia, GO. 66p.

Tollersrud T., Norstebo P.E., Engvik J.P., Andersen S.R., Reitan L.J. \& Lund A. 2002. Antibody responses in sheep vaccinated against Staphylococcus aureus mastitis: A comparison of two experimental vaccines containing different adjuvants. Vet. Res. Commun. 26:587600.

Tonin F.B. \& Nader Filho A. 2005. Correlação entre o "California Mastitis Test" e o exame bateriológico no leite de cabras. Ars Vet. 21:155159.

Turin L., Pisoni G., Giannino M.L., Antonini M., Rosati S., Ruffo G. \& Moroni P. 2005. Correlation between milk parameters in CAEV seropositive and negative primiparous goats during an eradication program in Italian farm. Small Rumin. Res. 57:73-79.

Ushimaru P.I., Silva M.T.N., Di Stasi L.C., Barbosa L. \& Fernandes Junior A. 2007. Antibacterial activity of medicinal plant extracts. Bras. J. Microbiol. 38:717-719.

Vilanova M., Gonçalves M., Osório M.T.M., Esteves R. \& Schmidt V. 2008. Aspectos sanitários do úbere e composição química do leite de cabras Saanen. Acta Scient. Vet. 36(3):235-240.

Zeng S.S. 1996. Comparisons of goat milk standards with cow milk standards of analyses somatic cell count, fat, and protein in goat milk. Small Rumin. Res. 21:221-225. 